\title{
A INDÚSTRIA BANCÁRIA BRASILEIRA: UM ESTUDO SOBRE AS BARREIRAS DE ENTRADA ÀS INSTITUIÇÕES ESTRANGEIRAS
}

\section{RESUMO}

O Brasil começou o ano de 2013 com o anúncio do Banco Central do Brasil-BCB sobre a possibilidade de autorizar a entrada de dezenove novos bancos estrangeiros. Por outro lado, barreiras de entrada existem em qualquer mercado. Elas são estruturais e dificilmente podem ser alteradas pelos potenciais entrantes. A pesquisa investiga quais as barreiras de entrada os bancos estrangeiros enfrentarão no mercado brasileiro. A teoria indicou quais barreiras deveriam ser pesquisadas, e outras específicas emergiram da consulta a 112 peritos (executivos, consultores e pesquisadores) do mercado bancário, sendo divididas em barreiras de mercado e institucionais. Foram consultados em 2013 o órgão regulador do sistema (BCB) e 39 bancos nacionais e estrangeiros. A análise foi descritiva e explicativa, com uso de análise fatorial e regressão logística. Para a análise foi considerada como variável dependente o tipo de banco (nacional ou estrangeiro), e como variáveis preditoras as barreiras de entrada. Como resultado, viu-se que as barreiras representativas são de mercado, enquanto as institucionais não mostraram significância, o que revela a força da indústria bancária no Brasil.

Palavras-chave: Tripé da Estratégia; Barreiras de Entrada; Indústria Bancária; Bancos Estrangeiros.

\section{THE BRAZILIAN BANKING INDUSTRY: A STUDY OF THE ENTRY BARRIERS TO FOREIGN INSTITUTIONS}

\begin{abstract}
Brazil began 2013 year with the announcement of the Central Bank of Brazil (BCB) on whether to authorize the entry of new nineteen foreign banks. Moreover, there are barriers to entry in any market. They are structural and can be hardly changed by potential entrants. The research investigates what are the entry barriers the foreign banks will face in the Brazilian market. The theory indicated the barriers should be surveyed, and other specific barriers emerged from consultation with 112 experts from the banking market. They were divided into market barriers and institutional barriers. The research consulted in 2013 the national regulator bank (BCB) and 39 domestic and foreign banks. The analysis was descriptive and explanatory using factor analysis and logistic regression. For the analysis it was considered as dependent variable the type of bank (domestic or foreign), and as predictors variables the entry barriers. As a result, it was seen that the barriers of market are representative and the institutional barriers showed no significance, which shows the strength of the banking industry in Brazil.
\end{abstract}

Keywords: Tripod Strategy; Entry Barriers; Banking Industry; Foreign Banks. 
A Indústria Bancária Brasileira: Um Estudo sobre as Barreiras de Entrada às Instituições Estrangeiras

\section{LA BANCA BRASILEÑA: UN ESTUDIO DE BARRERAS DE ENTRADA EXTERIORES INSTITUCIONES}

\section{RESUMEN}

Brasil comenzó el año 2013 con el anuncio de que el Banco Central de Brasil-BCB sobre la conveniencia de autorizar la entrada de nuevos bancos extranjeros diecinueve. Por otro lado, existen barreras de entrada en cualquier mercado. Ellos son estructurales y difícilmente pueden ser cambiados por los participantes potenciales. La investigación que investiga las barreras a la entrada de bancos extranjeros se enfrentan en el mercado brasileño. La teoría indica que se inspeccionarán las barreras, y otra específica que surge de la consulta a 112 expertos (ejecutivos, consultores e investigadores) del mercado bancario y se divide en las barreras institucionales y de mercado. Fueron consultados en el año 2013 el sistema regulador (BCB) y 39 bancos nacionales y extranjeros. El análisis fue descriptivo y explicativo, utilizando el análisis factorial y la regresión logística. Para el análisis se consideró como variable dependiente el tipo de base de datos (nacional o extranjera), y como predictores las barreras de entrada. Como resultado, se vio que las barreras son representativos del mercado, mientras que mostraron ninguna significación institucional, que muestra la fuerza de la industria bancaria en Brasil.

Palabras clave: Estrategia de Trípode; Las Barreras de Entrada; Sector de Actividades Bancarias; Los Bancos extranjeros.

Juliana Rabelo Melo ${ }^{1}$ Sérgio Henrique Arruda Cavalcante Forte ${ }^{2}$ José Milton de Sousa Filho ${ }^{3}$

1 Mestre em Administração de Empresas pelA Universidade de Fortaleza - UNIFOR. Brasil. E-mail: julianadmelo@yahoo.com.br

${ }^{2}$ Doutor em Administração de Empresas pela Fundação Getúlio Vargas - FGV. Professor da Universidade de Fortaleza

- UNIFOR. Brasil. E-mai: sergioforte@unifor.br

${ }^{3}$ Doutor em Administração de Empresas pela Fundação Getúlio Vargas - FGV. Professor da Universidade de Fortaleza

- UNIFOR. Brasil. E-mai: miltonsousa@unifor.br 


\section{INTRODUÇÃO}

O interesse pelo mercado nacional é evidenciado pelo número de entrada de instituições financeiras estrangeiras no país. De acordo com o BCB-Banco Central do Brasil (BCB, 2012a), a participação das instituições financeiras no patrimônio líquido do SFN-Sistema Financeiro Nacional foi de $18,44 \%$ em 2011, 15,64\% em 2010, 17,38\% em 2009 e $18,78 \%$ em 2008, em uma média de 17,56\%. Em 2012, a participação do capital estrangeiro no patrimônio líquido do SFN foi de 14,65\% (BCB, 2013b). A ameaça externa contra esse patamar no SFN, segundo a Fundação Getúlio Vargas (FGV, 2012), é o efeito da crise européia, que deve causar queda nas exportações e diminuição da oferta de crédito internacional. No mercado doméstico, o principal fator de desaceleração da economia deve ser a alta dos juros para conter a inflação gerada pelo consumo.

O Brasil começou 2013 com o anúncio do BCB sobre a possibilidade de autorizar a entrada de dezenove novos bancos estrangeiros (BCB, 2013a; Valor Econômico, 2013).

Por outro lado, barreiras de entrada existem em qualquer mercado. São estruturais e dificilmente podem ser alteradas pelos potenciais entrantes, o que as define como "condicionantes estruturais do comportamento das firmas" e não o inverso, e podem ter efeito minimizado caso o novo concorrente já tenha experiência, ou seja, em mercado correlato, uma vez que isto pode lhe proporcionar recursos que dão condição de competição. No entanto, a lucratividade do entrante está sujeita à intensidade da reação da(s) empresa(s) já estabelecida(s). Logo, a força da concorrência potencial passa a ser definida segundo a formação de expectativas no mercado (Fagundes \& Pondé, 1998). Nas palavras de Porter (1989), isso decorre do contexto estratégico de defesa do mercado onde a empresa atua.

Para Porter (1986), as barreiras variam de acordo com o recurso, podendo ser classificada como tecnológica, regulatória, informacional, de escala, de produto, capital, mudança, distribuição, custos, e política. Para Martins (2003), a 'altura' da barreira é medida pela dificuldade que ela impõe ao potencial concorrente, sobretudo no que se refere aos preços praticados e aos custos em médio e longo prazos.

Diante do exposto, a pergunta que motiva esta pesquisa é "Na visão da indústria bancária, quais são as barreiras de entrada aos bancos estrangeiros no mercado brasileiro?".

Buscando uma resposta ao problema de pesquisa, definiu-se como objetivo geral avaliar as barreiras de entrada aos bancos estrangeiros no mercado brasileiro sob a ótica da indústria bancária. Para tanto, outros três objetivos específicos são complementares, dada a complexidade do tema. A saber:
1. Identificar, sob o ponto de vista dos bancos estrangeiros instalados no Brasil, as barreiras à entrada no mercado brasileiro;

2. Agrupar as barreiras de entrada no intuito de entender melhor o fenômeno;

3. Investigar as percepções dos bancos nacionais e estrangeiros quanto à intensidade dessas barreiras;

Os resultados revelam quais barreiras nacionais oferecem maior dificuldade para os bancos estrangeiros no âmbito institucional (ambiente onde a regulamentação é definida), e no de mercado, onde a concorrência pode limitar a permanência da atuação. A relevância dos resultados é ainda mais significativa para gestores de instituições nacionais voltados para operações no Brasil porque, de posse dessas informações, podem direcionar esforços a fim de potencializar a intensidade das barreiras significativas para os bancos estrangeiros. Para os bancos estrangeiros esta pesquisa pode ajudá-los na elaboração de estratégias para penetrar no mercado bancário brasileiro. Para o campo acadêmico esta pesquisa é mais uma importante estudo que demonstra a força de três grupos de barreiras (de mercado, institucionais e de inovação).

A estrutura do trabalho se divide em: contextualização, problematização da pesquisa, objetivos, referencial teórico para embasar análises, coleta de dados, análise dos resultados, e conclusão.

\section{REFERENCIAL TEÓRICO}

\subsection{Barreiras de entrada}

O primeiro registro que se tem sobre reação de empresas já estabelecidas a potenciais entrantes, com foco econômico, data de 1952, quando Harrod (1952) registrou que se não há dificuldade de ingresso no setor, é sinal de que os operadores tendem a trabalhar com margens pequenas, aproximando os preços dos custos. Com a expressão 'barreiras de entrada', a primeira publicação é de Bain (1956), onde as consideram correguladores de conduta e desempenho das atividades empresariais. Desde então, muito já foi discutido sobre o assunto, em diferentes mercados e abordagens, como: os impactos que novos entrantes causam na rentabilidade de empresas já atuantes no mercado (Amel \& Liang, 1997); economias de escala, excesso de capacidade, preço e diferenciação do produto (Siegfried \& Evans, 1994); o efeito da ameaça de entrada no preço (Baumol, Panzar \& Willig, 1982; Harrod, 1952); a diferença de lucro em curto e longo prazos quando há concorrentes (Gaskins, 1971); a cadeia de valor do competidor (Porter, 1989); vantagens de custo das empresas já estabelecidas (Von Weizsäcker, 1980); inovação (Martin, 2002) e a natureza da estrutura de custos (Baumol et al.,1982). 
A Indústria Bancária Brasileira: Um Estudo sobre as Barreiras de Entrada às Instituições Estrangeiras

Segundo Bain (1956), existem três fatores que influenciam diretamente a entrada de novos competidores: (1) vantagem de custo; (2) diferenciação do produto, e (3) economia de escala. Para Porter (1986, p. 25), os limites/barreiras são "determinados pela indústria e por seu ambiente mais amplo".

Zaheer (1995) diz que o resultado de pesquisas aponta que a maioria das barreiras de entrada tem se concentrado, principalmente, em duas variáveis de mercado: (1) economias de escala e de produtos; (2) diferenciação; e outras de cunho não mercadológico (cuja orientação é pautada em variáveis institucionais, como leis e acordos entre empresas de mesmo setor). Baumol et al. (1982) e Martin (2002) dizem que, embora o mercado sofra com ameaça de novos concorrentes, a potencial entrada é uma variável que não pode ser observada e que, a reação é, no máximo, a de preparar-se estrategicamente para a concorrência.

Porter (1986) classifica barreiras de entrada em três tipos: (1) Barreiras Tecnológicas (os investimentos em tecnologia capazes de gerar competitividade frente aos rivais já consolidados no mercado. O volume dos recursos a serem investidos em aquisição ou aprimoramento tecnológico depende de quão dependente de tecnologia é a atividade); (2) barreiras regulatórias (legislação vigente); (3) barreiras “informacionais". Para Porter (1986)

devem ser consideradas também sete tipos de barreiras que o próprio mercado impõe e que, ao adotálas, está configurada uma estratégia de competição, seja ela ofensiva ou defensiva. São elas: Economia de Escala; Diferenciação do Produto; Necessidade de Capital; Custos de Mudança; Acesso aos Canais de Distribuição; Desvantagem de Custo independente de Escala, que se divide em: (a) tecnologia própria (desenvolvimento de patentes, métodos inovadores de produção); (b) know-how (conhecimento específico adquirido com a experiência); (c) acesso a matériasprimas (acesso às melhores matérias-primas, com condições especiais cedidas pelos fornecedores); (d) curva de aprendizagem (e) localização (empresa instalada em região onde tem acesso facilitado aos fornecedores e consumidores); e Política Governamental.

Conhecer e entender as barreiras que existem no setor, o poder de barganha e capilaridade dos players, os produtos disponíveis, os recursos dos competidores, e o ambiente regulatório torna o ambiente menos adverso. Peng (2008) orienta que as instituições devem ser vistas para além das abordagens de competitividade, recursos e riscos, e que outros três aspectos devem ser avaliados: a empresa como organismo; como integrante do mercado nacional; e como competidora internacional. Para todos estes, perpassam três riscos inerentes à instituição: (1) Riscos de Regulamentação (associados às políticas governamentais, e a possibilidade de que o governo algumas vezes também é competidor direto); (2) Barreiras Comerciais (barreiras tarifárias e não tarifárias; exigências de conteúdos locais - produto fabricado "em âmbito doméstico" e sujeito a barreiras tarifárias e não tarifárias); (3) Riscos Monetários (especulação - a confiança em relação à estabilidade/circulação da moeda; cobertura em outros países - atividades em diferentes zonas de circulação para que, em caso de prejuízo, o resultado de outra região possa compensar).

Além destes três riscos, existe também o que Hofstede (1980) chamou de barreiras culturais. Em geral, as barreiras culturais são a principal razão das movimentações estratégicas das organizações porque permitem distinguir os membros de cada grupo, e passam a categorizar a concorrência, influenciando na decisão de outros agentes. Peng (2008) posiciona-se em favor do papel estratégico da cultura.

A perspectiva analítica da Visão Baseada em Recursos (Barney \& Herstely, 2011) se completa quando os recursos tangíveis são mensurados, e os intangíveis são vistos como competências, o que significa incluir a experiência e aprendizado organizacional como ativos sob o ponto de vista do conhecimento de mercados específicos e as metodologias de gestão dos ativos como estratégia de autodefesa (barreiras de entrada).

O tema tem sido largamente pesquisado, com importância reconhecida por profissionais de mercado e acadêmicos. As muitas publicações mostram que o tema tem vasta aplicação, incluindo setor de serviços como discorrem Goldbaum (2006), Heger e Kraft (2008), Ivy Planning Group LLC Rockville (2000), Mcafee, Mialon e Williams (2004); a indústria com os trabalhos de Martins (2003), Karakaya e Stahl (1989), Snider e Williams (2011). As pesquisas acadêmicas se diferenciam pela contribuição que oferecem, sobretudo quando a abordagem pode trazer resultados que se aproximam do que a prática mostra. Barreiras de mercado estão fortemente presentes em relatórios gerenciais como os divulgados pelo The Economist (2006), e pelo Regulatory Policy Institute (2013).

\subsection{Participação dos bancos estrangeiros no sistema financeiro nacional}

Para Oliveira e Forte (2008), o ambiente competitivo seguido de forte crescimento tem forçado os agentes do setor financeiro a adaptar-se mesmo estando expostos a um constante grau de alerta. Em números, a participação estrangeira tem crescido nos últimos cinco anos, e assumiu outro perfil no SFNSistema Financeiro Nacional: em 2001, havia 86 bancos com capital de origem estrangeira (participação estrangeira, controle estrangeiro, de capital estrangeiro). Em 2007, essa participação caiu para 66 bancos (BCB, 2007). Em 2009, o número de bancos com capital estrangeiro voltou a crescer. De 2009 a 2012, a taxa média de crescimento foi de 7,08\% (BCB, 2013b). 
A entrada de novas instituições com controle estrangeiro e a expansão de suas atividades no país evidencia que o Brasil continua sendo foco de interesse de grupos internacionais como opção estratégica para expandir os seus negócios. O interesse dos bancos estrangeiros pelo mercado latino é expressivamente maior que pelos mercados de países desenvolvidos, o que faz das atividades internacionais uma extensão das atividades que se iniciam nacionalmente pelos bancos. Isso fica evidenciado de que segundo o Banco Central há mais pedidos de bancos estrangeiros para entrar no Brasil do que de bancos nacionais buscando mercado externo. (Geleilate \& Forte, 2012)

As instituições financeiras estrangeiras com capital votante no SFN, em novembro de 2013, somaram 172, entre instituições com controle estrangeiro (cujo capital votante a participação estrangeira é maior que 50\%), e com participação estrangeira (cujo capital votante a participação estrangeira é maior que $10 \%$ e menor que $50 \%$ ) (BCB, 2013c).

Em novembro de 2013, grupos estrangeiros de 24 nacionalidades compunham a participação de capital externo do SFN.

Em 2012, sete instituições com sede no exterior conseguiram autorização para operações e ou modificações societárias, e outras sete tiveram homologação de intenção de participação de capital estrangeiro (BCB, 2013b). Das sete solicitações para representação, cinco são de bancos europeus, uma é chinesa, e uma canadense. Somados a esses sete novos entrantes, existem dezenove pleitos (incluindo os que não estão formalmente registrados) (BCB, 2013a).

\section{MÉTODO}

\subsection{Tipo e Coleta de Pesquisa}

A pesquisa é de natureza descritiva para que sejam identificadas as variáveis que se revelam determinantes e secundárias sobre o fenômeno estudado (Machado, Maia \& Baraldi, 2007). A estratégia de pesquisa escolhida foi o método survey, uma vez que se pretendeu produzir descrições quantitativas da população pesquisada (FREITAS et al., 2000).

A primeira etapa constou de um levantamento bibliográfico na literatura de estratégia sobre barreiras, bem como material secundário empírico técnico e institucional. Em uma segunda etapa foram consultados 112 expertises, solicitando a eles uma listagem de possíveis barreiras que os bancos estrangeiros enfrentariam para ingressar no mercado bancário brasileiro. De posse da listagem teórica e do mercado bancário brasileiro. Em uma terceira etapa, e de forma complementar, entrevistou-se o diretor de economia da FEBRABAN-Federação Brasileira de Bancos, para se preparar para a coleta com os bancos no Brasil.
Em uma quarta foram encaminhados emails para todos os bancos nacionais e estrangeiros do país: (i) bancos nacionais e estrangeiros listados no site do BCB-Banco Central do Brasil e classificados como: múltiplo, comercial, investimento, desenvolvimento, e caixa econômica, e (ii) o próprio $\mathrm{BCB}$, como órgão regulador do SFN.

Os bancos nacionais e estrangeiros foram pesquisados para se investigar se a visão que os bancos estrangeiros têm sobre a intensidade das barreiras de entrada no mercado nacional é similar a dos bancos nacionais.

O recorte temporal (cross-sectional) corresponde ao período de 2008 a 2012. Os últimos cinco anos foram escolhidos considerando a dinamicidade do setor, período pós-crise do subprime, crise nos mercados europeu e norte-americano e, também, com o intuito de minimizar possíveis erros na avaliação das informações, uma vez que o BCB vem modificando a metodologia de pesquisa e o número de informações disponibilizadas nos relatórios do SFN. No período anterior a 2008, as informações publicadas são limitadas e não têm a mesma periodicidade praticada hoje.

O questionário tem duas perguntas objetivas, com as barreiras de entrada (de mercado e institucionais), a serem classificadas pelos respondentes de acordo com a intensidade que representa para o setor bancário nacional, na escala likert variando de 0 a 4, sendo: 0 (nula), 1 (fraca), 2 (moderada), 3 (forte), e 4 (muito forte). São 25 barreiras de mercado e 17 barreiras institucionais. Essas perguntas objetivam a avaliação das barreiras de entrada em relação à potencial entrada de bancos estrangeiros no Brasil, pela indicação da intensidade de cada uma, tendo como base a ótica de cada tipo de instituição: órgão regulador (BCB), e bancos nacionais e estrangeiros.

A população da pesquisa com os bancos configurou-se como um censo (Freitas et al., 2000) aplicado aos 178 bancos dispostos no site do BCB. Os questionários foram configurados no Survio, e seus respectivos links foram enviados por correio eletrônico para a relação de emails, previamente confirmados como ativos e corretos, de bancos nacionais e estrangeiros, e para emails de três diretores do BCB disponíveis nos respectivos sites.

Para identificar as respostas quanto ao tipo de instituição (nacionais, estrangeiras, reguladora), decidiu-se criar três grupos de plataformas de respostas on-line: Grupo I (BCB), Grupo II (110 bancos nacionais), e Grupo III (67 bancos estrangeiros com operações no Brasil). A pesquisa não solicitou identificação do respondente, e tinha link vinculado exclusivamente ao questionário.

O questionário foi enviado quinzenalmente, a partir de abril/2013. Até a terceira semana de julho/2013, quando a pesquisa foi encerrada, foram obtidas 21 respostas dos bancos nacionais, 17 dos 
A Indústria Bancária Brasileira: Um Estudo sobre as Barreiras de Entrada às Instituições Estrangeiras

bancos estrangeiros, e uma do BCB, ou seja, 39/181, representando $22 \%$ da população.

As respostas obtidas foram exportadas para o SPSS (Statistical Package for Social Science), onde foram extraídos todos os dados descritivos da pesquisa $\mathrm{e}$, posteriormente, aplicados métodos de análise multivariada.

\subsection{Técnica de Análise de Dados}

Após a avaliação da estatística descritiva, a análise dos dados foi feita em duas etapas: na primeira, foi utilizada a Análise Fatorial Exploratória (AFE). Na segunda, Regressão Logística (RL).

\subsubsection{Análise Fatorial-AF}

A aderência do método está no objetivo da AFE: método exploratório que busca, por meio da avaliação das variáveis, identificar dimensões de variabilidade comuns num conjunto de fenômenos, com o intuito de desvendar estruturas existentes, mas não observáveis diretamente (fatores), e sem exigir prévia determinação de relação de dependência entre elas (Corrar, Paulo \& Dias Filho, 2012, p. 74).

Embora a teoria ainda não tenha definido um número absoluto de amostras e, dada a dificuldade em conseguir respostas quando se trata da indústria bancária, optou-se por adotar como critério o teste Kaiser-Meyer-Olkim (KMO), que indica o grau de explicação dos dados a partir dos fatores encontrados na análise fatorial (Corrar et al., 2012: p. 100). O teste Kaiser recomenda que o valor do teste maior que 0.5 é aceitável e, caso obtenha valor inferior, que seja feita nova coleta de dados, ou que sejam excluídas algumas variáveis. Para o caso de exclusão de variáveis, Field (2009, p. 571) aconselha que sejam escolhidas aquelas que não se correlacionam com outras variáveis. Para Corrar et al. (2012), a fim de que não haja perda de informações, às variáveis excluídas devem ser reaplicadas a análise fatorial, e em seguida observar se há formação de novos fatores, observando se o valor do KMO valida a reaplicação.

Outro fator que motivou o uso da análise fatorial foi a defesa de Field (2009, p.65) da precisão do critério Kaiser quando o número de variáveis é menor que 30 (caso desta pesquisa), e as comunalidades (após extração) têm valores maior que 0,7 .

O método de extração das dimensões latentes entre as variáveis trabalhadas foi o de Componentes Principais, que busca combinações lineares entre as variáveis, e repete o processo até que a máxima variância explicada seja alcançada. Para a rotação dos dados (reagrupamento das cargas fatoriais mantendo a variância total obtida reorganizando os autovalores, e maximizando as cargas sobre cada valor), optou-se pela Varimax, uma vez que minimiza a possibilidade da existência de alta carga fatorial em diferentes dimensões, o que facilita a identificação dos elementos (Corrar et al., 2012). Para Hair et al. (2011), na Varimax, existe a possibilidade de altas cargas (próximas de -1 ou de +1 ) e também de cargas próximas de zero. Se forem altas, indica forte influência das variáveis que se aproximam do fator. Para o segundo caso, indica influência quase nula de variáveis sem importância para a formação dos grupos.

\subsubsection{Regressão Logística}

Com a indicação de quais barreiras de entrada têm maior intensidade/influência para os bancos no mercado nacional, decidiu-se utilizar a Regressão Logística (RL) porque "busca explicar/predizer valores de uma variável em função de valores conhecidos de outras variáveis", trabalha com variável dependente binária (bancos nacionais ou bancos estrangeiros), e seu resultado possibilita "associações a certas categorias, tais como positivo ou negativo, aceitar ou rejeitar" e permitem "interpretações em termos de probabilidade e não apenas classificações em categorias" (Corrar et al., 2012, p.283).

A primeira pergunta sobre a metodologia de estimação se refere ao porquê de sua utilização ao invés de, por exemplo, optar pela Estimação OLS, ou Análise Discriminante. Hair et al. (2011) justificam dizendo que seria impossível manter os critérios de homocedasticidade ou normalidade, e que, portanto, a RL é o método mais adequado a esta pesquisa. Corrar et al. (2012) atestam ainda que, associada à escolha da RL, está o pequeno número de suposições que a envolve, permitindo ao pesquisador sobrelevar restrições impostas por vários outros modelos multivariados, além da fácil compreensão da complexidade do método e dos resultados.

Sobre a amostra utilizada, tomou-se como orientação a recomendação de Hair et al. (2011: p.319), que diz que a dimensão da amostra recomendada é, pelo menos, 10 observações para cada parâmetro estimado. Ademais, a análise dos dados foi dividida em duas fases: AFE, e RL. Neste trabalho a RL teve a função de verificar a probabilidade de ocorrência dos resultados encontrados na AFE. Logo, a RL foi aplicada a um reduzido número de variáveis.

A equação genérica utilizada foi:

$$
\log \frac{p}{(1-p)}=\alpha+\beta_{1} \alpha_{1}+\beta_{2} \alpha_{2}+\cdots+\beta_{n} \alpha_{n}
$$

A fim de avaliar a evolução do modelo estimado, utilizou-se a estratégia backward stepwise. De acordo com a argumentação de Field (2009), estima-se o modelo com todos os regressores e são testadas possíveis exclusões de regressores para verificar se existe mudança significativa no grau de aderência, além do princípio da parcimônia, para o qual o método backward é mais indicado. Isso ocorre porque o efeito supressor, que ocorre quando um 
previsor tem efeito significativo somente se outra variável se mantém constante (Field, 2009, p. 228).

O modelo empírico encontrado foi:

$$
\log \frac{p}{(1-p)}=\alpha+\beta_{i} B M_{i}+\beta_{n} B I_{n} \text {, Onde: } B M=
$$

Barreiras de Mercado; $i=$ iésimos fatores de mercado. $B I=$ Barreiras Institucionais; $n=$ enésimos fatores institucionais.

\section{RESULTADOS E DISCUSSÃO}

De posse dos dados, a análise se deu em três etapas: Análise descritiva, Análise Fatorial Exploratória, Regressão Logística.

\subsection{Análise Descritiva - Frequência das Respostas}

A análise descritiva foi realizada para que os resultados preliminares pudessem ser destacados. Utilizando a ferramenta do 'formatação condicional' do Excel, foram analisadas somente as barreiras que tiveram frequência de resposta acima de $50 \%$.

Sobre as Barreiras de Mercado, para os Bancos Nacionai, das 25 inicialmente trabalhadas no questionário, 11 apresentaram frequência de resposta maior que $50 \%$, sendo seis de fraca intensidade. O grau de internacionalização mostrou-se bastante significativo, seguido das variáveis "economia de escala, empreendedorismo, retaliações anteriores, alianças, e poder de reação". Com moderada intensidade, as barreiras têm frequência praticamente homogênea $(57 \%)$ nas barreiras indicativas sobre funding, governança, diferenciação de produtos, e gestão da carteira.

Para os Bancos Estrangeiros, sete barreiras têm a maior frequência de resposta, sendo cinco classificadas como de forte intensidade, e referem-se à maturidade, retaliações, rivalidade, distribuição, e gestão de recursos de terceiros.

Sobre as Barreiras Institucionais, tanto para os bancos nacionais quanto para os estrangeiros, as que tiveram frequência maior que 50\% são classificadas como de forte intensidade. Para os Bancos Nacionais, política governamental, moeda e cadastro positivo são as mais importantes. Para os Bancos Estrangeiros, a estabilidade econômica, subsídios oficiais, cultura de negócios no Brasil e segurança são as mais relevantes.

\subsection{Análise Fatorial}

Os dados foram tratados separadamente por tipo de barreira: de mercado, e institucional. Para as de mercado, a AF indicou formação de seis fatores, e de sete para as institucionais. O teste Kaiser-Meyer-Olkin measure of sampling adequacy (KMO) que indica valores de 0 a 1 , sendo o mínimo valor uma evidência de que a amostra utilizada não se adapta a esta análise pela divergência no padrão de correlação. O máximo valor indica forte aderência à técnica por correlações convergentes (Field, 2009).

Os resultados encontrados na $\mathrm{AF}$ foram: (i) barreiras de mercado - 0,57 (limite inferior); (ii) barreiras institucionais - 0,46 (abaixo do limite inferior). Seguindo a orientação de Field (2009) e Corrar et al. (2012) foram analisadas as matrizes antiimagem de correlação a fim de avaliar a adequação de cada variável pela diagonal principal da matriz. As que apresentavam valores abaixo de 0,5 foram eliminadas e a $\mathrm{AF}$ foi reaplicada até que fosse encontrado um valor de KMO satisfatório. No segundo recálculo, encontrouse o valor de 0,756 , que foi considerado como adequado.

O recálculo final da anti-imagem de correlação mostrou sete variáveis explicativas para as barreiras institucionais. Foram retiradas: (i) Política governamental restritiva à entrada de novos concorrentes; (ii) Estabilidade da economia brasileira; (iii) Risco Brasil; (iv) Concentração da indústria bancária brasileira; (v) Representatividade da indústria bancária no PIB brasileiro; (vi) Cultura e ética de negócios bancários no Brasil; (v) Nível de corrupção; (vi) Segurança física e patrimonial; (vii) Barreira informacional (dificuldade de acesso à informação); (viii) Falta de compartilhamento de informação positiva (cadastro positivo). Foram encontrados dois fatores, com variância total explicada de 62,04\%.

Ao Fator 1, nominou-se de 'aspectos econômicos e legais, composto por: macroeconomia brasileira, baixo nível de poupança nacional, custo de conversibilidade da moeda Real, subsídios oficiais, e sistema de leis, regulamentos e regras na indústria bancária brasileira. $\mathrm{O}$ segundo fator, Fator 2, foi nominado 'normas do BCB', com: poder das instituições fiscalizadoras do SFN, e depósito compulsório alto. A reaplicação da análise não resultou em combinações relevantes (KMO abaixo de 0,5), nem tampouco na matriz anti-imagem de correlações, permanecendo dois fatores no total.

Dentre as sete barreiras que formam os dois fatores (econômicos e legais, e normas BCB), apenas três foram sugeridas pelos experts, sendo as demais retiradas do referencial teórico de Porter (1986), Peng (2008), Nakane e Pessoa (2011) e OECD (2008).

Para as barreiras de mercado, foram feitos quatro recálculos de matriz anti-imagem de correlação para encontrar variáveis com poder de explicação do fenômeno (valores da diagonal principal acima de 0,5). Alcançou-se o KMO de 0,759, e o número de variáveis foi reduzido a 17. Foram encontrados quatro fatores para as barreiras de mercado, com 62,04\%. Foram retiradas: (i) Grau de rivalidade dos bancos do Brasil; (ii) Necessidade de capital para atendimento do Basiléia III; (iii) Força da participação dos bancos estrangeiros no Brasil; (iv) Governança corporativa dos bancos; (v) Gestão de recursos de terceiros; (vi) Marca dos bancos; (vii) Canais de distribuição dos bancos; (viii) Aprendizagem/experiência no mercado bancário 
A Indústria Bancária Brasileira: Um Estudo sobre as Barreiras de Entrada às Instituições Estrangeiras

brasileiro; (ix) Competência dos recursos humanos dos bancos.

As barreiras de mercado foram agrupadas em quatro fatores, nominados segundo as barreiras de cada um. Fator 1: aspectos concorrenciais (retaliações anteriores à entrada de bancos estrangeiros; poder atual de reação à ameaça de entrantes potenciais; poder de barganha dos clientes; importância das atividades não bancárias). Fator 2: maturidade estratégica (localização da sede do banco; capacidade e maturidade estratégica no Brasil). Fator 3: inovação (diferenciação dos produtos e serviços; tecnologia e sistemas de informação; capacidade de inovação das instituições bancárias ou parabancárias em substituição aos serviços ofertados pelos bancos e economia de escala). Fator 4: atuação dos bancos (grau de internacionalização dos bancos brasileiros; e custo de mudança de carteira).

A fim de que não fosse perdida nenhuma informação, e para se manter a consistência do trabalho, foi feita outra análise das variáveis excluídas das duas classificações de barreira, onde foi verificada a possibilidade de formação de novos fatores (Corrar et al., 2012). Foram encontrados outros dois fatores para as barreiras de mercado, cuja variância explicada alcança 72,42\%. Foram excluídas (obedecendo ao mesmo critério de exclusão dos primeiros) quatro variáveis (duas pelo método de análise da matriz antiimagem de correlação, e duas pela comunalidade inexpressiva), e as restantes geraram KMO de 0,749 (valor similar ao encontrado anteriormente).

O primeiro novo fator encontrado (aspectos gerenciais) é composto por: grau de rivalidade dos bancos do Brasil; marca dos bancos; fidelidade dos clientes; e canais de distribuição dos bancos. O segundo (aspectos administrativos) compreende: governança corporativa dos bancos; e gestão de recursos de terceiros. Ao final, tem-se 6 fatores referentes às barreiras de mercado.

Das 22 barreiras dos seis fatores apresentados pela AFE, nove barreiras foram retiradas do referencial teórico. As demais foram sugeridas pelos experts entrevistados.

O grande número de variáveis não referenciadas teoricamente, mas formadoras de fatores resultantes da aplicação da AFE, pode ser derivado de indicações de variáveis originalmente brasileiras, uma vez que todos os entrevistados são de instituições que operam na indústria bancária brasileira e, portanto, podem ter considerado, sobretudo, as características do mercado local. Sendo assim, além da aplicação do referencial, esta pesquisa mostra que existem muitas outras barreiras de entrada a serem consideradas para a indústria bancária brasileira.

\subsection{Regressão Logística - RL}

A RL foi feita utilizando a divisão resultante da aplicação da AFE, e o primeiro ponto que merece explicação sobre a RL está no critério de seleção utilizado para a estratégia backward stepwise, de onde se preferiu pela utilização da estatística Wald. Testa-se, portanto, de como as oito dimensões conseguidas na AFE assumidas como variáveis explicativas à origem do banco, sendo duas obtidas para as Barreiras Institucionais (IN), enquanto as outras seis são definidas a partir das Barreiras Mercadológicas (MN).

$\mathrm{O}$ primeiro resultado apresentado aponta para o fato de que quatro das observações não possuem valor, portanto apenas 34 são utilizadas nas estimações.

Em seguida é disponibilizada a indicação de que o modelo apenas com a constante (modelo de referência) explicaria $50 \%$ dos casos, portanto esperase que a utilização das dimensões obtidas na AFE supere este nível de explicação.

A seguir apresentam-se os testes Omnibus para os coeficientes do modelo, que assume como hipótese nula que todos os parâmetros estimados são iguais a zero. Após seis passos, indicando que possivelmente seria a opção por um modelo com três variáveis, foi possível, sobre qualquer um deles, dizer que pelo menos um dos parâmetros estimados é diferente de zero (Model Chi-square).

Na avaliação do sumário do modelo, onde são apresentados os Likelihood Value, bem como dois Pseudo- $\mathrm{R}^{2}$, os resultados combinam os seis passos do modelo, tendo em vista a intenção de avaliar suas evoluções.

A fim de mitigar possibilidade de dúvida sobre a utilização de um dos cinco primeiros modelos (apresentados nos Steps 1-5), a observação do out put esclarece que nenhum destes modelos foi possível resolver com 20 iterações e, portanto, os resultados não apresentam 'consistência' em nenhuma das três estatísticas de teste.

Os resultados não permitem fazer uma avaliação da evolução no Likelihood Value (dado por 2Log likelihood) porque, como explicam Corrar et al. (2012) este valor precisaria ser comparado a estatísticas de outros modelos, a fim de que fosse possível definir padrão de melhora ou piora em cada um dos passos (steps) na medida em que fossem retiradas as variáveis que estariam enviesando o modelo. Para os dois Pseudo- ${ }^{2}$, entretanto, é possível fazer considerações: no Cox \& Snell $R$ Square indica que explica $64,2 \%$ da variação da variável dependente (tipo de banco). O Nagelkerke $R$ Square (com valor máximo 1 e mínimo $0)$ indica que o modelo com estas três dimensões permite explicar $85,6 \%$ das variações nas variáveis independentes.

O último teste avaliado antes dos resultados do modelo 6 (step 6), é o de Hosmer e Lemershow, que admite como hipótese nula a inexistência de diferenças significativas entre os resultados preditos em comparação com os observados. Este teste também não demonstra resultados interessantes nos cinco primeiros modelos. No sexto, a hipótese nula $(p$-value $=0,567)$ é 
A Indústria Bancária Brasileira: Um Estudo sobre as Barreiras de Entrada às Instituições Estrangeiras

mantida, indicando sua consistência para determinar a origem dos bancos.

No primeiro modelo apresentado, o percentual de acerto foi de $50 \%$. No sexto, o percentual foi de $94,1 \%$. Erro! Fonte de referência não encontrada.O Teste Wald possibilita a indicação de que todos os três resultados são estatisticamente diferentes de zero a um nível de confiança de $95 \%$.

A equação que permite realizar predições com o sexto modelo é:

$P($ evento $)=\frac{1}{1+e^{(-2,87+6,69 A C+5,31 M E+4,81 \mathrm{NOV})}}$
A equação final da RL, com as variáveis é:

$$
\log \frac{p}{(1-p)}=-2,87+6,69 A C+5,31 M E+4,811 \text { NOV }
$$

Aplicando a média aritmética das respostas/opiniões de cada tipo de banco, para cada barreira correspondente aos grupos AC, ME, e INOV, tem-se a probabilidade percebida de cada tipo de banco em relação às barreiras. Foram seguidos os passos:

I. Seleção das barreiras para os respectivos grupos (Tabela $1)$ :

Tabela 1 - Média de Respostas das Variáveis que Compõem os Fatores.

\begin{tabular}{|c|c|c|c|}
\hline BARREIRAS DE MERCADO & Bancos & Bancos & \\
\hline Retallacoes anterlores à entrada de bancos estrangelros & 1,66 & 2,86 & \\
\hline Poder atual de reaçăo à ameaça de entrantes potenclals & 1,85 & 3,01 & \\
\hline Poder de barganha dos cllentes & 1,82 & 2,70 & \\
\hline Importâncla das atividades nåo bancárlas ou parabancárlas em & 1,65 & 2,71 & \\
\hline Economla de escala (custos diluidos pela alta escala de produtos & 1,66 & 2,82 & \\
\hline Funding dos Bancos no Brasll & 1,83 & 2,83 & \\
\hline Formaçăo de allanças estratéglcas & 1,62 & 2,63 & \\
\hline Locallzaçăo da sede dos bancos & 2,20 & 2,86 & \\
\hline Capacidade e maturidade estratéglcas dos bancos no Brasil & 2,19 & 2,90 & \\
\hline Diferenclaçฐ̃o dos produtos e servlços: & 2,03 & 2,88 & \\
\hline Fidelidade dos cllentes & 2,04 & 2,80 & \\
\hline Comunicação e marketing Institucional & 1,96 & 2,78 & \\
\hline Tecnologla e Sistemas de Informaçåo & 2,45 & 2,83 & \\
\hline Capacidade de Inovaç̃o das Institulç̧̃es bancárlas & 1,97 & 2,87 & \\
\hline Grau de rivalidade dos bancos no Brasil & 1,66 & 2,60 & \\
\hline Força da Participaçăo dos bancos estrangeiros no Brasil & 1,88 & 2,81 & \\
\hline Empreendedorismo dos bancos no Brasil & 1,70 & 2,68 & \\
\hline Grau de internacionalizaçăo dos bancos brasileiros & 1,67 & 2,74 & \\
\hline Custos de mudança de carteiras (comercial, investimento etc.) & 1,83 & 2,79 & \\
\hline Governança corporativa dos bancos & 1,85 & 2,82 & \\
\hline Gestăo de recursos de terceiros & 1,98 & 2,79 & \\
\hline Marca dos bancos & 1,93 & 2,88 & \\
\hline Canais de distribuiçăo dos bancos & 1,99 & 2,88 & \\
\hline Aprendizagem/experiência no mercado bancário brasileiro & 2,35 & 2,90 & \\
\hline Competéncia dos recursos humanos dos bancos & 2,23 & 2,88 & \\
\hline \multicolumn{4}{|l|}{ Legenda: } \\
\hline Aspectos Concorrencias (AC) & \multicolumn{3}{|c|}{ Inovaçăo (INOV) } \\
\hline
\end{tabular}

Nota. Fonte: Elaborado pelos autores. 
A Indústria Bancária Brasileira: Um Estudo sobre as Barreiras de Entrada às Instituições Estrangeiras

II. Cálculo da média aritmética de cada barreira, por grupo e por tipo de banco (Tabela 2):

Tabela 2 - Médias por Grupo (AC, ME, INOV)

\begin{tabular}{|lcc|}
\hline & Bancos Nacionais & Bancos Estrangeiros \\
\hline Aspectos Concorrenciais & 1,74 & 2,82 \\
\hline Maturidade Estratégica & 2,01 & 2,80 \\
Inovação & 2,09 & 2,83 \\
\hline
\end{tabular}

Nota. Fonte: Elaborado pelos autores.

III. Aplicação das médias aritméticas na equação final da RL (Tabela 3):

Tabela 3 - Aplicação da Equação da RL

\begin{tabular}{|l|c|c|c|c|c|c|c|c|}
\hline & \multirow{2}{*}{ Constante } & \multicolumn{2}{|c|}{ AC } & \multicolumn{3}{c|}{ ME } & \multicolumn{3}{c|}{ INOV } & \multirow{2}{*}{ p(eveno) } \\
\cline { 3 - 8 } & & Peso & Média & Peso & Média & Peso & Média & \\
\hline Bancos Nacionais & $-2,87$ & 6,69 & 1,74 & 5,31 & 2,01 & 4,81 & 2,09 & $29,50 \%$ \\
Bancos Estrangeiros & $-2,87$ & 6,69 & 2,82 & 5,31 & 2,80 & 4,81 & 2,83 & $44,48 \%$ \\
\hline
\end{tabular}

Nota. Fonte: Elaborado pelos autores.

Para os bancos nacionais, a probabilidade percebida em relação às barreiras de entrada nacionais é de 29,50\%. Para os bancos estrangeiros, é de $\mathbf{4 4 , 4 8 \%}$, indicando que as barreiras de mercado brasileiras, sob a opinião dos bancos, são mais intensas para os bancos estrangeiros.

De acordo com a RL, os grupos de barreiras têm 'pesos' diferentes entre si, sendo o grupo dos 'aspectos concorrenciais' o maior, com 6,69, seguido pelo 'maturidade estratégica', com 5,31 e, por último, o 'inovação', com 4,81. Ou seja, o que representa maior ameaça aos bancos estrangeiros.

Das 25 propostas no questionário, $14 \mathrm{se}$ destacaram, sendo classificadas em três grupos (todas elas barreiras de mercado): (i) Aspectos Concorrenciais - AC (retaliações anteriores à entrada de bancos estrangeiros; poder atual de reação à ameaça de entrantes potenciais; poder de barganha dos clientes; importância das atividades não bancárias ou parabancárias em substituição aos produtos e serviços ofertados; economia de escala (custos diluídos pela alta escala de produtos e serviços oferecidos); funding dos bancos no Brasil); (ii) Maturidade Estratégica - ME (formação de alianças estratégicas; localização da sede dos bancos; capacidade e maturidade estratégicas dos bancos no Brasil); (iii) Inovação - Inov (diferenciação dos produtos e serviços; fidelidade dos clientes; comunicação e marketing institucional; tecnologia e sistemas de informação; capacidade de inovação das instituições bancárias). A distribuição das barreiras em cada grupo não significa hierarquia de intensidade, uma vez que não é essa a função da RL.

Dentre os três grupos, o que abriga maior número de barreiras, é o Aspectos Concorrenciais, com seis barreiras. Dentre essas, destacam-se a reação do mercado interno com duas variáveis que sinalizam seu perfil agressivo: 'Retaliações anteriores à entrada de bancos estrangeiros', e 'Poder atual de reação à ameaça de entrantes potenciais'. $67 \%$ das barreiras foram indicadas por experts, e $33 \%$ retiradas do referencial teórico, conforme Figura 1. 
A Indústria Bancária Brasileira: Um Estudo sobre as Barreiras de Entrada às Instituições Estrangeiras

BARREIRAS DE MERCADO - ASPECTOS CONCORRENCIAIS

1. Retaliações anteriores à entrada de bancos estrangeiros

2. Poder atual de reação à ameaça de entrantes potenciais

3. Funding dos Bancos no Brasil

4. Importância das atividades não bancárias ou parabancárias em substituição aos produtos e serviços ofertados pelos bancos

5. Poder de barganha dos clientes

6. Economia de escala (custos diluídos pela alta escala de produtos e servicos oferecidos)

REFERÊNCIA

Expert setor bancário

Expert setor bancário

Expert setor bancário

Expert setor bancário

Porter (1986), Peng (2008)

Porter (1986)

Figura 1 - Referências das barreiras - Grupo Aspectos Concorrenciais

Nota. Fonte: Elaborado pelos autores.

Das três do grupo ME, uma foi indicada por expert na elaboração do questionário, e as outras duas

retiradas do referencial teórico de Porter (1986) e Peng (2008) (Figura 2):

\begin{tabular}{|l|c|c|}
\hline BARREIRAS DE MERCADO - MATURIDADE ESTRATÉGICA & REFERÊNCIA & \\
\hline 1. Formação de alianças estratégicas & Expert setor bancário & ஸे $^{\circ}$ \\
\hline 2. Localização da sede dos bancos & Porter (1986) & $\circ{ }^{\circ}$ \\
3. Capacidade e maturidade estratégicas dos bancos no Brasil & Peng (2008) & 6 \\
\hline
\end{tabular}

Figura 2 - Referências das barreiras - Grupo Maturidade Estratégica

Nota. Fonte: Elaborado pelos autores.

O grupo Inovação tem variáveis que representam as ações inovadoras dos bancos nacionais, como a 'Diferenciação dos produtos e serviços',
'Tecnologia e sistemas de informação'. Tem $60 \%$ das barreiras oriundas do referencial teórico, e $40 \%$ indicadas por experts, conforme Figura 3:
BARREIRAS DE MERCADO - INOVACCÃO

1. Fidelidade dos clientes

2. Comunicação e marketing institucional

3. Diferenciação dos produtos e serviços

4. Tecnologia e sistemas de informação

5. Capacidade de inovação das instituições bancárias

\section{REFERÊNCIA}

\begin{tabular}{|c|c|}
\hline $\begin{array}{l}\text { Expert setor bancário } \\
\text { Expert setor bancário }\end{array}$ & o̊ \\
\hline Porter (1986), Peng (2008) & \\
\hline Porter (1986) & \\
\hline Peng (2008) & \\
\hline
\end{tabular}

Figura 3 - Referências das barreiras - Grupo Inovação Nota. Fonte: Elaborado pelos autores.

De todas as barreiras pesquisadas no questionário, apenas 14 se mostraram significativas ao final da aplicação das ferramentas estatísticas, sendo sete oriundas da indicação dos experts.

\section{CONCLUSÃO}

Em resposta ao objetivo específico 1, a pesquisa apontou a barreiras de mercado como as principais enfrentadas pelos bancos estrangeiros, ao contrário das indicações de Nakane (2011) que aponta que as principais barreiras têm se concentrado em três variáveis: (i) juros elevados; (ii) baixa poupança e, principalmente (iii) a inconversibilidade da moeda (neste trabalho classificadas como barreiras institucionais); e Sacconato e Jensen (2010) com elementos como estrutura física, alto grau de burocratização, e interferência estatal caracterizada na manipulação de impostos como o IOF (imposto sobre operações financeiras).

Para o BCB as barreiras institucionais não impedem a entrada de bancos estrangeiros no mercado brasileiro, pois depois da fase de 'motivação', se o pedido de ingresso no mercado nacional não for negado ainda como manifestação informal, o BCB tenta convencer a instituição a formalizar o pedido e, então, inicia a avaliação sobre "uma série de questões além do óbvio e, em princípio, o saudável aumento da concorrência" e que mesmo com tanto rigor é "raríssimo o BCB reprovar algum pedido formal" (BCB, 2013b). Ou seja, o resultado vai ai encontro desta informação, já que o BCB como órgão regulador do sistema bancário não impõe barreiras.

A resposta para o objetivo específico 2 mostra no resultado da $\mathrm{RL}$ com os grupos de barreiras de mercado de maior intensidade: AC, ME e Inov. Para o objetivo específico3, a resposta foi alcançada com a aplicação da equação final da RL, com o resultado que 
A Indústria Bancária Brasileira: Um Estudo sobre as Barreiras de Entrada às Instituições Estrangeiras

indica probabilidade percebida para os bancos estrangeiros ser de 44,48\%.

$\mathrm{O}$ resultado obtido, além de confirmar o constructo sobre barreiras nas colaborações de Porter (1989) e Peng (2008), está de acordo com Zaheer (1995) quando diz que pesquisas apontam que a maioria das barreiras de entrada se concentra, principalmente, em duas variáveis de mercado: (1) economias de escala e de produtos (Grupo AC), e (2) diferenciação (Grupo Inov). Cita também outras variáveis de cunho não mercadológico (cuja orientação é pautada em variáveis institucionais) que, neste caso, podem ser 'formação de alianças estratégicas'(Grupo $\mathrm{ME})$.

A contribuição está, sobretudo, nas barreiras de mercado identificadas nas entrevistas com experts, representando $50 \%$ do resultado final indicado pelas ferramentas estatísticas.

Para o mercado, essas informações são importantes para empresas/bancos que buscam ferramentas que potencializem sua estratégia, e mitiguem os efeitos da concorrência, sobretudo porque a maior contribuição está no grupo 'Aspectos Concorrenciais', tendo $67 \%$ das barreiras que não estão em registros acadêmicos.

Os três grupos de barreiras resultantes da RL têm ligação entre si. Embora só um seja nominado 'aspectos concorrenciais', na verdade, 'maturidade estratégica' e 'inovação' também agrupam barreiras que 'protegem' o mercado interno, e dificultam a entrada de instituições estrangeiras. A maturidade estratégica alcançada pelo setor é transversal aos outros grupos porque a capacidade de inovar e de concorrer também é resultado da experiência e aprendizado na operação.

Os 'pesos' dos grupos de barreiras resultantes da RL mostram que 'aspectos concorrenciais' é o de maior significância na percepção dos bancos (objetivo específico 3). Isso talvez derive do fato que os bancos brasileiros a cada ano se tornam mais fortes $\mathrm{e}$ experientes, possibilitando a criação de barreiras cada vez mais difíceis de superar para um banco estrangeiro, sobretudo quando se considera o desconhecimento do como a indústria brasileira opera. Embora a equação mostre 'pesos' diferentes, na prática, as ações de concorrência são complexas e interligadas, e exigem maturidade estratégica e inovação. Existe ainda um ponto a ser discutido. Trata-se da permanência dos bancos estrangeiros no mercado brasileiro. $\mathrm{O}$ ingresso se inicia pela autorização do BCB. No entanto, o que parece ser a fase mais difícil é, em verdade, a mais simples. Isso porque estar no mercado bancário brasileiro significa, além de vencer a barreira do desconhecimento de um novo mercado (PENG, 2008), precisa também superar as barreiras impostas pelo mercado nacional. A permanência do player estrangeiro depende não somente da competência/experiência do operador, mas, sobretudo, das condições que o mercado impõe. No caso do
Brasil, significa enfrentar um mercado maduro, agressivo, ágil, e com tecnologia bancária que está entre as dez mais fortes do mundo (FEBRABAN, 2013), e distribuir-se num território geograficamente extenso (IPEA, 2011), onde os três maiores bancos (Banco do Brasil, Bradesco, Itaú), ao final de 2013, tinham 14.004 agências (BCB, 2013).

A pesquisa teve a limitação de uma amostra reduzida, o que pode ter impactado no resultado final.

No tratamento estatístico, foram utilizados todos os recursos que poderiam minimizar a perda de dados, a exemplo da segunda aplicação da AFE nas barreiras de mercado. O processo de elaboração do questionário também contribui para assegurar a qualidade das respostas obtidas (embora não possa garantir a fidedignidade dos respondentes), uma vez que foi preliminarmente aprovado na fase pré-teste com experts do setor bancário.

Claramente existe muito ainda a ser pesquisado sobre o setor bancário. $\mathrm{O}$ mercado bancário brasileiro ainda tem muitos escopos a serem explorados academicamente, como: (i) O cenário de competição entre as instituições brasileiras e as estrangeiras; (ii) $\mathrm{O}$ que há em comum entre os bancos que conseguiram permanecer no mercado brasileiro; (iii) Quais as estratégias utilizadas pelos estrangeiros para superar a concorrência no mercado brasileiro; (iv) Como os bancos brasileiros lidam com a concorrência estrangeira; (v) $\mathrm{O}$ impacto que a chegada de bancos estrangeiros causa no SFN; (vi) Como o sistema financeiro global vê o SFN; (vii) Quais as perspectivas de crescimento no mercado bancário brasileiro para bancos estrangeiros; (viii) $\mathrm{O}$ que motiva o reingresso de instituições estrangeiras no mercado bancário brasileiro.

Há muito espaço para pesquisas adicionais sobre as decisões dos gestores de bancos, embora seja muito difícil de acessá-los, e de conhecer a razão pela conduta de mercado adotada.

\section{REFERÊNCIAS}

Amel, D. F.\&Liang, J. N. (1997).Determinants of Entry and Profits in Local Banking Markets. Review of Industrial Organization, 12: 59-78.

Bain, J. (1956).Barriers to New Competition. Cambridge, Mass: Harvard University. (Capítulo 1. Tradução do original em inglês. UNICAMP, mimeo).

Baumol, W. J., Panzar, J. C.\& Willig R.D. (1982). Constetable Markets and the Theory of Industry Structure. New York: Harcourt Brace Jovanovich. 
BCB. Banco Central do Brasil. (2007). Relatório de evolução do SFN. Disponível em: <www.bcb.gov.br>. Acesso em: 9 abr 2013.

(2012). Relatório de Estabilidade Financeira - mar/2012. Disponível em: <www.bcb.gov.br>. Acesso em: 10 abr 2012.

(2013a) Relatório de Estabilidade Financeira - mar/2013. Disponível em: <www.bcb.gov.br>. Acesso em: 7 abr 2013.

(2013b). Relatório de evolução do SFN mar/2013. Disponível em: <www.bcb.gov.br>. Acesso em: 7 abr 2013.

(2013c). Composição e evolução do SFN out/2013. Disponível em: <http://www.bcb.gov.br/?SFNATUALMES>. Acesso em: 15 out 2013.

Barney, J. B.\& Hesterly, W.S. (2007). Administração Estratégica e Vantagem Competitiva.São Paulo: Pearson Prentice Hall.

Corrar, L. J., Paulo, E.\& Dias Filho, J. M. (Coord.) (2012). Análise Multivariada: Para cursos de Administração, Ciências Contábeis e Economia. São Paulo: Atlas.

Fagundes, J. \& Pondé, J. (1998). Barreiras à Entrada e Defesa da Concorrência: Notas Introdutórias. Texto para Discussão $n^{\circ} 1$, Cadernos de Estudo, Universidade Cândido Mendes.

FEBRABAN. Federação Brasileira de Bancos. (2013). Pesquisa FEBRABAN de Tecnologia Bancária 2013: O Setor Bancário em Números. Disponível em:

<http://www.febraban.org.br/7Rof7SWg6qmyvwJc FwF7I0aSDf9jyV/sitefebraban/Pesquisa\%20FEBR ABAN\%20de\%20Tecnologia\%20Banc\%E1ria\%20 2013.pdf > Acesso em: 27 jun 2013.

Field, A. (2009). Descobrindo a estatística usando o SPSS. Porto Alegre: Artmed.

Freitas, H., Oliveira, M., Saccoi, A.Z. \& Mascarola, J. (2000). O método de pesquisa survey. Revista de Administração, São Paulo, v.35, n.3: 105-112, jul/set.

FGV. Fundação Getúlio Vargas. (2012). The Brazilian Economy - economy, politics and policy issues, Publicação Fundação Getúlio Vargas, v. 4, n. 11: $1-37$

Gaskins, D. W. (1971). Dynamic Limit Pricing: Optimal Pricing Under Threat or Entry. Journal of Economic Theory, 3: 306-322.
Geleilate, J. M. G.; Forte, S.H. A.C. (2012). Motivações e estratégias de internacionalização dos três maiores bancos brasileiros frente à nova configuração econômica mundial. Revista Portuguesa e Brasileira de Gestão, Lisboa, v. 11, n. 1: $2-12$

Goldbaum, S. (2006). Regressão linear múltipla para análise das barreiras à entrada em mercados monopolizados: a distribuição de automóveis. São Paulo: Prêmio Seae.

Hair, J. F. et al. (2011). Fundamentos de métodos de pesquisa em administração 6. ed. Porto Alegre: Bookman.

Harrod, R. F. (1952). Economic Essays. New York: Macmillan.

Heger, D. \& Kraft, K. (2008). Barriers to Entry and Profitability. University of Dortmund - Department of Economics. Institute for the Study of Labor (IZA).

Hofstede, G. (1980). Culture's consequences: International differences in work-related values. Beverly Hills, CA: Sage.

Ivy Planning Group Llc Rockville. (2000). Market Entry Barriers, Discrimination and Changes in Broadcast and Wireless Licensing. The Office of General Counsel Federal Communications Commission.

Karakaya, F.\& Stahl, M. J. (1989). Barriers to entry and market entry decisions in consumer and industrial goods markets. Journal of Marketing. v. 53, April: 80-91.

Machado, L. M.; Maia, G. Z. A.; Baraldi, A.C.F. (2007). Pesquisa em educação: passo a passo. Marília, SP: M3T Tecnologia e Educação, 176 p. Disponível em: <http://books.google.com.br/books?id=BXGdZKM O5t8C\&pg=PA62\&dq=pesquisa + survey $\&$ hl $=$ pt BR\&sa=X\&ei=5ZuvUu_vBouPkAf3tYHwBA\&ve $\mathrm{d}=0$ CEMQ6AEwAA\#v=onepage $\& \mathrm{q}=$ pesquisa $\% 20 \mathrm{~s}$ urvey $\& \mathrm{f}=$ false $>$. Acesso em: 16 dez. 2013.

Martin, S. (2002). Advanced Industrial Organization. 2. ed. MA: Blackwell, Malden.

Martins, C. A. (2003).Introdução da Concorrência e Barreiras à Entrada na Atividade de Refino de Petróleo no Brasil. 2003. 129 f. Dissertação (Mestrado) - Curso de Mestrado em Economia, Departamento de Instituto de Economia, Universidade Federal do Rio de Janeiro, Rio de Janeiro. 
A Indústria Bancária Brasileira: Um Estudo sobre as Barreiras de Entrada às Instituições Estrangeiras

Mcafee, P., Mialon, H. M.\& Williams, M. A. (2004).When are sunk costs barriers to entry? American Economic Review, v. 94, n.2, May: 461465.

Mintzberg, H.\& Quinn, J. B. (2001). O Processo da Estratégia. 3. ed. Porto Alegre: Bookman.

Nakane, M.I. \& Pessoa, S. (2011). A estabilização incompleta. Disponível em: <http://www.tendencias.com.br/news.cgi?id=44>. Acesso em 14 jun.2011

OECD. (2008). Annual report on competition policy developments in Brazil. OECD Competition Committee.Disponível em: <http://www.oecd.org/brazil/34720245.pdf >. Acesso em: 07 fev 2011.

Oliveira, O. V.\& Forte, S. H. A. C.(2008). Banking industry: constructing prospective scenes and identifying strategies. Faces (FACE/FUMEC), v. 7, n.2: $29-47$

Peng, M. E. (2008). Estratégia Global. São Paulo: Thomson Learning.

Porter, M. E . (1986). Estratégia Competitiva: Técnicas para Análise de Indústrias e da Concorrência. 7. ed. Rio de Janeiro: Elsevier.

(1989). Vantagem Competitiva: Criando $e$ Sustentando um Desempenho Superior. Rio de Janeiro: Elsevier, 1989.

Regulatory Policy Institute. (2003). Understanding barriers to entry, exit and changes to the structure of regulated legal firms - final report.
Sacconato, A. \& Jensen, J. (2010). A política econômica que não foi discutida nas eleições publicado no jornal Valor Econômico em 12.11.2010. Disponível em:〈www.tendencia.inf.br/news.cgi?id=31> Acesso em: 27 ago. 2011.

Siegfried, J. J. \& Evans, L. B. (1994). Empirical Studies of Entry and Exit: A Survey of the Evidence. Review of Industrial Organization, 9: 121-155.

Snider, C.\& Williams, J. W. (2011). Barriers to Entry in the Airline Industry: A Regression Discontinuity Approach. Clemson University, NYU. Disponível em:

<http://www.econ.ucla.edu/people/papers/Snider/S nider507.pdf>. Acesso em 2 jan 2013.

The Economist. (2006). Barriers to Entry Coping with Protectionism: A report from the Economist Intelligence Unit Commissioned by UK Trade \& Investment. The Economist Intelligence Unit,

Valor Econômico.(2013). Brasil atrai mais 19 bancos estrangeiros. Disponível em: <http://www.valor.com.br/financas/3058252/brasilatrai-mais-19-bancos-estrangeiros $>$. Acesso em: 28 mar 2013.

VonWeizsäcker, C. C. (1980). A Welfare Analysis of Barriers to Entry. Bell Journal of Economics, 11: 399-420.

Zaheer, S. (1995). Overcoming the Liability of Foreignness. Academy of Management Journal. v. 38, n. 2: 341-363 